\title{
Perceptions of an evidence-based empathy mobile app in post-secondary education
}

\section{Lisa B. Hoplock ${ }^{1}$ (i) $\cdot$ Michelle M. Lobchuk ${ }^{1}$ (i) - Jocelyne Lemoine ${ }^{1}$ (I)}

Received: 24 June 2020 / Accepted: 20 August 2020 / Published online: 25 August 2020

(C) Springer Science+Business Media, LLC, part of Springer Nature 2020

\begin{abstract}
Cognitive empathy (also known as perspective-taking) is an important, teachable, skill. As part of a knowledge translation project, we identified a) interest in an evidence-based cognitive empathy mobile app and b) which faculties believe that cognitive empathy is important for their profession. Students $(n=638)$ and instructors/professors $(n=38)$ completed a university-wide survey. Participants in Education, Social Work, and the Health Sciences were among those most interested in the app. The majority of participants said that they would prefer for the app to be free or less than $\$ 3$ for students. Most participants preferred a one-time payment option. Across 17 faculties, all but one had $60 \%$ or more of its sampled members say that cognitive empathy is important for their profession. Results illuminate perceptions of cognitive empathy instruction and technology. Results also provide insight into issues to consider when developing and implementing an educational communication app.
\end{abstract}

Keywords Perspective-taking $\cdot$ Mobile learning $\cdot$ Empathy $\cdot$ Mobile application · Knowledge-to-action

\section{Perceptions of an evidence-based empathy mobile app in post-secondary education}

Students want communication skills training (Keyworth et al. 2013), and seem to appreciate the opportunity for self-reflection and self-growth (Cunico et al. 2012). One such important skill is cognitive empathy. Cognitive empathy (also known as perspective-taking) involves understanding a person's perspective from that person's point of view (Lobchuk et al. 2016). Although engaging in cognitive empathy does not always result in positive outcomes (e.g., people can arrive at a negative self-view when

Michelle M. Lobchuk

Michelle.Lobchuk@umanitoba.ca

1 Rady Faculty of Health Sciences, College of Nursing, University of Manitoba, 89 Curry Place, Winnipeg, Manitoba R3T 2N2, Canada 
self-reflecting; Hoplock and Lobchuk 2019; Vorauer 2013), it has been linked to positive outcomes such as increased patient compliance and satisfaction within healthcare (Kim et al. 2004), engaging in prosocial behavior (Davis 2015), team effectiveness, and engaging in high quality communication (Parker et al. 2008). People vary in their ability to engage in cognitive empathy, but fortunately, it is a skill that can be taught (e.g., Brunero et al. 2010; Richardson et al. 2015; Teding van Berkhout and Malouff 2016). One way that cognitive empathy can be taught is by using technology (e.g., Lobchuk et al. 2018). The present research examines people's perceptions of a cognitive empathy-training mobile app as well as how perceptions of cognitive empathy's importance vary by profession.

\subsection{Cognitive empathy}

Cognitive empathy is studied in a variety of fields, such as healthcare (e.g., BlanchHartigan and Ruben 2013; Lobchuk et al. 2016, 2018), psychology (e.g., Marangoni et al. 1995; Vorauer and Sasaki 2014), business (e.g., Ku et al. 2015), and law (e.g., Bandes 2009). One frequently-used paradigm involves filming an interaction between two people, having the interaction members report what they were thinking and feeling throughout the interaction, having the interaction members guess what the other person was thinking and feeling throughout the interaction, and then providing an accuracy score (Ickes 2001). This accuracy score indicates how accurate a person is at inferring the thoughts and feelings of another. Accuracy is associated with relationship satisfaction (Sened et al. 2017; Thomas and Fletcher 2003), skillfully providing social support (Verhofstadt et al. 2016), and accommodating during conflict (Kilpatrick et al. 2003). Thus, accuracy is helpful for facilitating successful communication and relationships across contexts.

People's perspective-taking ability improves when they are self-aware of personal values/emotions that can thwart empathy (Lobchuk et al. 2012); receive instruction (Lelorain et al. 2012) and feedback (Noordman et al. 2012), and self-evaluate with video-feedback (Fukkink et al. 2011). The authors have been conducting iterative research on an intervention that takes these findings into consideration, incorporating Ickes' (2001) paradigm and including perspective-taking instruction. However, currently, the intervention involves coming into a lab for the filming. To increase accessibility and cost-effectiveness, the intervention could be adapted as a mobile app for use within any setting, not just the classroom.

\subsection{Mobile learning}

Most students world-wide own a smartphone (e.g., Farley et al. 2015; Nason et al. 2015; O’Connor and Andrews 2018; Williamson and Muckle 2018). While mobile devices such as smartphones and tablets (Crompton and Burke 2018) are sometimes seen as a distraction in the classroom, they are increasingly being leveraged to facilitate learning (Langmia and Glass 2014; Nguyen et al. 2015). Indeed, with classes being forced online due to COVID-19, it is expected that instructors will incorporate technology into their courses more than ever before (Bates 2020). It is important that devices are used in a way that facilitates taking an active role in learning (Norris et al. 2011). When they are used in that way, mobile devices may improve student 
motivation and productivity (Cotter et al. 2015), confidence (Koohestani et al. 2018), and performance (Dunleavy et al. 2019; Hsueh et al. 2018). For example, a recent metaanalysis of healthcare research on using mobile technology within education (mLearning) found that participants who experienced mLearning tended to have superior knowledge and skills than those who received traditional education (Dunleavy et al. 2019). Thus, growing evidence supports the use of mLearning. We are interested in people's perceptions of using an app for teaching and practicing cognitive empathy.

\subsection{Present research}

Research findings do not always get translated into practice in fields like education, and it can take a long time for them to be implemented if they do (Burkhardt and Schoenfeld 2003). We follow the Canadian Institutes of Health Research Knowledge to Action Process (KTA; Government of Canada 2016) framework to expedite the integration of our evidence-based intervention into students' learning activities. According to this framework, knowledge is created (e.g., through research) and then translated into application through an iterative cycle. Knowledge creation includes inquiry, synthesis, and product-creation (Government of Canada 2016). We aim to move our research towards the product-creation phase and ensure that it becomes incorporated more quickly into practice.

We currently conduct the intervention with students from a variety of healthcare disciplines (e.g., nursing, occupational therapy, kinesiology; (e.g., Lobchuk et al. 2016, 2018). One version of the intervention has also included videoconferencing (Hoplock and Lobchuk 2019b). Yet, this intervention could be made more accessible if it were converted to mobile technology. Many students and instructors/professors own mobile devices and use apps, making them the ideal population to assess the potential use of mobile learning for educational purposes in an academic setting.

It is important to conduct market research with the population of interest (university students and instructors/tenure-track and tenured professors), so that we understand potential app users and the merit of creating the app before we start creating it. We want to ensure that what we create is meaningful to the people who will use it and that it will be used within communication skills curricula. To date, we have conducted intervention research with health professionals. However, it is possible that the potential intervention user-base is larger than just those in the health profession (e.g., law, education, or business). Thus, we circulated a university-wide survey to students and instructors/professors to better understand who might be interested in the intervention and cognitive empathy.

The purpose of the present research is to identify the target market, demand, and price point as well as to solicit student and instructor/professor perceptions of the empathy-training mobile app. We had the following research questions:

- Research Question 1: Who would want to use this app?

- Research Question 2: What do people from the target population think of the app idea? 
- Research Question 3: Which professions believe that cognitive empathy is important to their profession? ${ }^{1}$

This work may appeal to people who study empathy, education technology, marketing, and business. This research may also help people who want to create related apps. Cognitive empathy is a valuable skill for successful interpersonal relationships (e.g., Batson and Ahmad 2009; Davis 2009; Davis 2015; Galinsky et al. 2005) and so converting a successful intervention to be able to teach empathy accessibly is a worthy goal.

\section{Materials and methods}

After obtaining ethics approval, we conducted a survey to answer our research questions. In accordance with Simmons et al. (2011, 2012), we report how we determined our sample size, all data exclusions, all experimental manipulations (there were none), and all study measures.

\subsection{Participants}

Our aim was to give all students and instructor/professors the opportunity to describe their opinions or attitudes toward our empathy application. A census sampling frame was determined to be most appropriate. This sampling frame aims to collect information from every eligible member of the population. Our decision was not to exclude any student or instructor/professor at the University so as to boost our success in accruing a representative sample of students and faculty by taking a census sampling approach. Because this work was exploratory, we did not conduct a formal power analysis. Instead, we aimed to recruit at least 300 students (Hao et al. 2017) and 100 instructors/professors (Vrana 2018) or as many participants as we could before our stopping rule: complete data collection by the end of December, 2018 (approximately 1 month after data collection started). We chose this stopping rule due to time constraints. Participation was restricted to students and instructors/professors over the age of 18. Approximately 30,000 students and 1100 instructors/professors were emailed a survey link; 1081 people accessed the survey. Data from 676 participants were retained (638 students; 38 instructors/professors) after exclusions ( $n=13$ did not provide consent; $n=391$ did not fully complete the survey; one person provided nonsensical responses). Most participants identified as white (66\% students, $86 \%$ instructors/professors) and as women (68\% students, $75 \%$ instructors/professors). The average ages of students and instructors/professors were 24.64 years $(S D=8.02)$ and 48.82 years $(S D=9.19)$ respectively.

\footnotetext{
${ }^{1}$ For transparency, we originally hypothesized that social (e.g., psychology, education) and life science (e.g., physiology, immunology) participants would a) believe that cognitive empathy is more important to their profession and b) would be more interested in the app than physical science (e.g., physics, chemistry) participants. However, categorizing the different departments after data collection proved difficult because some departments had within-department category overlap (e.g., biochemistry). Thus, too much error would have been introduced into the categorization and conclusions would not be drawn confidently. Therefore, we decided to forgo categorization and this analysis.
} 


\subsection{Procedure and measures}

Participants volunteered for an online study on "Perceptions of an Evidence-based Empathy Mobile App in Post-Secondary Education." At the start of December 2018, they were emailed a study description and link. They were told that they would have until the end of the month to complete the study. A reminder was sent mid-way through the month. Participants did not receive compensation.

Materials can be found on the Open Science Framework: https://osf.io/bh9 su/?view_only $=0 \mathrm{ff} 44 \mathrm{fe} 143914 \mathrm{e} 0088 \mathrm{c} 1 \mathrm{f5d} 54 \mathrm{ac} 7 \mathrm{f} 8 \mathrm{c} 6$. The majority of questionnaire items were author-created and inspired by the literature (e.g., Alwraikat and Tokhaim 2014; Sevillano-Garcia and Vazquez-Cano 2015; Vrana 2018). We obtained suitability and coverage feedback on our survey from experts in technology development at the university's Technology Transfer Office.

The overall structure of the questionnaire was the same for students and instructors/professors, however the content of the questions varied. Students completed questions regarding using the app as part of their education. Instructors/professors completed questions regarding using the app as a teaching resource as well as for personal use.

\subsubsection{App interest}

After providing informed consent, participants were first presented with a description of the app's purpose and how it would work. They saw two wireframes to give them a sense of the app idea and what the app might look like. Next, they were asked their perceptions of the app. Students rated their agreement on four statements $(1=$ strongly disagree, 7 = strongly agree), providing their perceptions of the app as being applicable to their profession, their perceptions of the app helping them to meet their needs, their liking using mobile learning as part of their educational curriculum, and their confidence in using mobile technology to achieve their learning goals. Instructors/professors were asked to rate their agreement with six similar statements using the same scale. Four of the statements related to using the app for teaching or professional work, one related to their perceptions of using mobile technology as an education tool, and one related to their confidence in using mobile technology to achieve their teaching goals. Participants then indicated their interest in the app, with faculty indicating both their interest in the app as a teaching tool (1 item) and their personal interest in the app (1 item; $1=$ very disinterested, $7=$ very interested . Using an open-ended question format, participants provided their reaction to the app (adapted to an open-ended question format from a 5-pt Likert scale from SurveyMonkey n.d.). They then indicated how likely they would be to consider buying the app $(1=$ extremely unlikely, $7=$ extremely likely; adapted from a 5-pt scale; SurveyMonkey n.d.). Those who selected 1 or 2 on the scale were asked an open-ended question regarding why they were unlikely to consider buying the app. Faculty were also asked how likely they would be to recommend that student buy the app $(1=$ extremely unlikely, $7=$ extremely likely; adapted from a 10-pt scale and to this context; SurveyMonkey n.d.). Those who selected 1 or 2 on the scale were asked an open-ended question regarding why they were unlikely to consider recommending buying the app. 


\subsubsection{Price point}

To better understand price point and pricing strategies, we asked participants to check all that apply when considering what one-time price they would feel comfortable paying for the app (\$0.00; \$0.01-\$0.99; \$1.00-\$2.99; \$3.00-\$5.99; over \$5.99), what payment type they would prefer (Subscription (1.e., several smaller payments); One-time payment (1.e., one larger payment)), and what payment version they would prefer (Consumers may choose between a basic version of the In Your Shoes Mobile App that is free and a version that has extra features and a cost; Consumers use a free trial of the In Your Shoes Mobile App with extra features and payment is required later). Students responded while imagining that the app was required in a course and then responded imagining that the app was not required in a course. Instructors/professors were asked what they would feel comfortable asking students to pay if the app was required in a course, and then if it was not required. Instructors/ professors were also asked what they themselves would pay if using the app for personal use.

\subsubsection{Target market and cognitive empathy's importance for professions}

Participants next completed demographics questions asking about gender, age, ethnicity, income (Statistics Canada 2020), smartphone or tablet ownership and use (Chen and deNoyelles 2013), device brand (adapted from Chen and deNoyelles 2013 to ask about what brand they primarily use instead of what device they own), hours spent on their phone or tablet for things related to work/school (Chen and deNoyelles 2013), whether they use an app for coursework (adapted from Chen and deNoyelles 2013 to ask whether they have used an app instead of how often), their faculty, college, department, and class format (in-person/in-class; online/distance; mix of in-class and online courses). Students were asked about their program year, degree, and student status. Instructors/ professors were asked their academic rank and teaching experience (the latter was adapted to include more options for those with fewer years of experience; Alwraikat and Tokhaim 2014). We also wanted to know if participants' respective programs had at least one course that focuses on interpersonal communication (yes, no, unsure). Those who answered "No" or "Unsure" were asked if interpersonal communication was incorporated into their curriculum to some degree. Finally, participants rated whether cognitive empathy was important for their profession $(1=$ not at all, $7=$ extremely $)$.

\subsection{Design and data analyses}

We employed a descriptive, cross-sectional, online survey with participants. With all students and instructor/professors at the University having been invited to participate, we had the opportunity to 'drill down' and conduct exploratory analyses of linkages between student and instructor/professor characteristics and their opinions or attitudes toward the empathy application.

\subsubsection{Quantitative methods}

Descriptive statistics (medians, means, standard deviations, frequency counts, and percentages) were used to describe the sample of students and instructor/professors, as well as address Research Questions 1 to 3. 


\subsubsection{Qualitative methods}

We ran the responses to the open-ended questions through a sentiment analyzer and a word cloud generator located on danielsoper.com to get an objective sense of participants' sentiment towards the product. Sentiment analyzers use "computational linguistics and text mining to automatically" determine the overall degree of negativity $(-100)$, neutrality (0), or positivity (100) in the text (Soper n.d.). Word cloud generators analyze text to determine whether certain words are used more frequently. A strength of these two approaches is that it analyzes the results impartially and, thus, will help validate results found using our other methods. A limitation of these approaches is that they examine the overall text, without nuance.

We also analyzed the responses to the open-ended questions using content analysis (see online supplemental materials for additional details; Lincoln and Guba 1985; Patton 2002). Credibility was established by recruiting participants from the target population (Elo et al. 2014). Dependability and confirmability were met with an audit trail documenting coding decisions and template development (e.g., Saldana 2009). Confirmability also occurred through independent coding and analysis and by an iterative feedback process until consensus was reached (Graneheim and Lundman 2004). We also used participants' own words for codes and themes when possible to ensure that we stayed close to the data (Levitt et al. 2018).

\section{Results}

There are 17 Faculties at the university. At least one student from every Faculty participated. Instructors/professors from 10 Faculties participated. Therefore, we obtained diversity in the Faculties that participated. Over $90 \%$ of participants owned and used a smartphone or tablet, and most participants (61.3\% students; $83.3 \%$ instructors/ professors) used Apple products. For students, $44 \%$ have used a mobile app required or suggested by their instructor for course work. For instructors/professors, 57\% have required or suggested to students to use a mobile app for course work. Most participants preferred the app to be free ( $41 \%$ of students; $34 \%$ of instructors/professors) or less than $\$ 3$ for students (56\% of students; $34.2 \%$ of instructors/professors). Participants also preferred a one-time payment option ( $85 \%$ of students; $66 \%$ of instructors/professors) as well as the ability to choose between a basic version of the app that is free and a version that has extra features and cost (74\% of students; $63 \%$ of instructors/professors; see online supplemental materials for other participant details).

\subsection{Who would want to use the app?}

Addressing Research Question 1 (who would want to use this app), 44\% of students and $53 \%$ of instructors/professors said that their program features at least one course that focuses on interpersonal communication. Of those who said that their program did not feature an interpersonal communication course or that they were not sure if it did, $33 \%$ of students and $53 \%$ of instructors/professors said that interpersonal communication is incorporated into the curriculum to some degree. Faculties from where most professors and instructors indicated that they had an interpersonal communication 
course in their program included Business, Education, Health Sciences, Law, and Social Work. Instructors/professors from the Arts, Education, Health Sciences, and Law were among those most interested in using the app as a teaching tool (Table 1). Instructor/professors from Business; Education; Environment, Earth, and Resources; and Law were interested in using the app for personal use (Table 2). Students in Agriculture; Art (e.g., Fine Art); Arts (e.g., Sociology); Education; Environment, Earth, and Resources; Health sciences; Music; Science; Social Work; Extended education; and University 1 (a Faculty for those just starting at the university) were interested in the app (Table 2). Thus, these Faculties may be a good target for uptake of the app.

When analyzing participants' reactions to the app, one theme that emerged, Target or Use Case, involved commenting on the target people or use case (i.e., when or in what contexts someone might use it) for the app. This theme's categories included that the participant thought the app was not relevant to them; the participant commented on who the target audience might be; and the participant commented on potential use cases for the app (Table 3). For example, one participant (woman, instructor/professor, Faculty of Agricultural and Food Sciences) wrote, "Looks great for areas where you need to communicate with a patient/client on more than one level. Not so much in my area." Another (man, student, Faculty of Health Sciences) wrote, "the app sounds fun and with right pricing could be helpful to new international students." These responses help narrow the target market.

\subsection{What do people think of the app idea?}

Addressing Research Question 2 (what people from the target population think of the app idea), sentiment analysis and word cloud generator results of the open-ended questions indicated that responses were generally neutral to negative. Students' responses to "What is your reaction to the In Your Shoes Mobile App" were neutral (0.3; possible range $=-100$ to 100$)$. The word cloud indicated that responses were focused

Table 1 Instructor/Professor interest in the App as a teaching tool by faculty area

\begin{tabular}{|c|c|c|c|c|}
\hline Faculty & Median & Mean & $\mathrm{SD}$ & $\mathrm{N}$ \\
\hline Faculty of Agricultural and Food Sciences & 3 & 2.67 & 0.58 & 3 \\
\hline School of Agriculture & 1 & 1 & - & 1 \\
\hline Faculty of Arts & 5 & 4.17 & 2.14 & 6 \\
\hline School of Business & 2.5 & 2.5 & 0.71 & 2 \\
\hline Faculty of Education & 6.5 & 6.5 & 0.71 & 2 \\
\hline Faculty of Environment, Earth, and Resources & 3.5 & 3.5 & 2.12 & 2 \\
\hline Faculty of Health Sciences & 5 & 5 & 1.7 & 10 \\
\hline Faculty of Law & 5 & 5 & - & 1 \\
\hline Faculty of Science & 3 & 3.17 & 1.33 & 6 \\
\hline Faculty of Social Work & 3.5 & 3.5 & 3.54 & 2 \\
\hline Did not indicate Faculty & 2 & 2.67 & 2.08 & 3 \\
\hline Total & 4 & 3.89 & 1.93 & 38 \\
\hline
\end{tabular}

Ratings were made on a 7-pt scale with higher numbers indicating greater interest in the app 
Table 2 Student and Instructor/Professor interest in the App for themselves by faculty area

\begin{tabular}{|c|c|c|c|c|c|c|c|c|}
\hline \multirow[t]{2}{*}{ Faculty } & \multicolumn{4}{|c|}{ Student responses } & \multicolumn{4}{|c|}{$\begin{array}{l}\text { Instructor/professor } \\
\text { responses }\end{array}$} \\
\hline & Median & Mean & SD & $\mathrm{N}$ & Median & Mean & SD & $\mathrm{N}$ \\
\hline Faculty of Agricultural and Food Sciences & 4 & 3.5 & 1.75 & 26 & 3 & 2.33 & 1.15 & 3 \\
\hline School of Agriculture & 6 & 6 & - & 1 & 1 & 1 & - & 1 \\
\hline Faculty of Architecture & 3.5 & 3.75 & 2.19 & 8 & - & - & - & - \\
\hline School of Art & 5 & 4.75 & 1.39 & 8 & - & - & - & - \\
\hline Faculty of Arts & 5 & 4.04 & 1.67 & 107 & 3.50 & 3.33 & 1.63 & 6 \\
\hline School of Business & 4 & 3.83 & 1.51 & 46 & 5 & 5 & 0 & 2 \\
\hline Faculty of Education & 6 & 5.07 & 1.87 & 15 & 5 & 5 & 1.41 & 2 \\
\hline Faculty of Engineering & 4 & 3.65 & 1.70 & 43 & - & - & - & - \\
\hline Faculty of Environment, Earth, and Resources & 4 & 4 & 1.73 & 15 & 4 & 4 & 2.83 & 2 \\
\hline Faculty of Health Sciences & 5 & 4.11 & 1.75 & 74 & 5 & 4.9 & 1.52 & 10 \\
\hline Faculty of Kinesiology and Recreation Management & 4 & 3.69 & 1.65 & 13 & - & - & - & - \\
\hline Faculty of Law & 3 & 2.6 & 1.14 & 5 & 5 & 5 & - & 1 \\
\hline Faculty of Music & 5 & 5 & 0 & 5 & - & - & - & - \\
\hline Faculty of Science & 5 & 4.09 & 1.61 & 108 & 3.5 & 3.5 & 1.52 & 6 \\
\hline Faculty of Social Work & 6 & 5.3 & 1.38 & 33 & 3 & 3 & 2.83 & 2 \\
\hline Extended Education & 5 & 4.92 & 1.24 & 12 & - & - & - & - \\
\hline University 1 & 5 & 4.5 & 1.76 & 80 & - & - & - & - \\
\hline Did not indicate Faculty & 5 & 4.6 & 1.90 & 35 & 1 & 1 & 0 & 3 \\
\hline Total & 5 & 4.18 & 1.71 & 634 & 4 & 3.68 & 1.85 & 38 \\
\hline
\end{tabular}

Ratings were made on a 7-pt scale with higher numbers indicating greater interest in the app

around empathy, apps, and the perception that the idea is interesting (see online supplemental materials for the word clouds). Instructor/professor responses were somewhat negative (-42.4). Their word cloud was somewhat similar to that of the students, but was also focused on students, teaching, and learning.

Diving deeper, when analyzing participants' reactions to the app, two additional themes emerged: participants described practical issues with the app, which might affect uptake and participants commented on the concept idea (Table 3). The first theme's categories included barriers to empathy and barriers relating to the intervention procedure. For example, one participant (man, student, University 1 Faculty) wrote, "Seems like a great idea but would be a little weird to find a partner to record conversations and get them to tag their thoughts and feelings." These responses help identify potential concerns and factors to watch out for when creating the app; for example, finding the right dialogue partner and drawing on a relevant context to engage in a meaningful dialogue. The second theme had four categories: 1) Positive reactions to the app idea (e.g., favourable evaluation of the app, willingness to try the app, and visualizing positive outcomes as a result of using the app); Negative reactions to the app idea (e.g., unfavourable evaluation of the app; doubts in teaching empathy with an app; negative comments about empathy training in general; and comments about the app not 
Table 3 Thematic reactions to the App by participants

Themes Examples

Practical issues with the app: Participant describes barriers to using the app, which might affect uptake

Barriers to empathy: Participant describes barriers that "It seems impractical - a lot of people would probably relate to empathy be very uncomfortable with the exercise described above and would not want to put in the time to tag a recording of their conversation." (woman, student, Faculty of Arts)

Procedure: Participant describes barriers that relate to "the instructions are a little complicated, which I the intervention protocol believe will prevent some students from using it unless they really want to put in effort. It would be better if scenerios (sic) were supplied in addition to this feature so it didn't require two people to use." (man, student, University 1)

Target or Use Case: Participant comments on the target people or use case for the app

Not relevant: Participant states that they do not believe "Not really relevant for my faculty" (man, student, that the app is relevant to them/their needs Faculty of Engineering)

Target audience: Participant comments on who might "A good idea for therapists in training" (woman, be interested in using the app or who should use the app student, Faculty of Health Sciences)

Use case: Participant comments on the use case for the "could be applicable in a marriage counselling app (i.e., when/in what contexts someone might use it) setting" (woman; student, Faculty of Health Sciences)

Concept idea: Participant makes a comment about the concept idea

Positive: Participant expresses a positive reaction to the app idea

Favourable evaluation: Participant expresses a favourable evaluation of the app

Would try: Participant indicates that they would like to use the app

Visualizing positive outcomes: Participant makes a statement reflecting expectations of positive outcomes as a result of using the app
"Cool" (woman, student, Faculty of Science)

"would try a trial version" (fluid femme, student, Faculty of Science)

"It might help me in understanding my customer's perspective and understand what they are feeling and thinking about my products/services." (man, student, School of Business)

Negative: Participant expresses a negative reaction to the app idea

Unfavourable evaluation: Participant expresses an unfavourable evaluation of the app

"boring" (woman, student, Faculty of Kinesiology and Recreation Management)

Doubts in teaching empathy with an app: Participant is uncertain about whether empathy can be taught using a mobile application

Unnecessary: Participant makes a negative comment about empathy training in general

Technology not useful: Participant comments that the app is not useful

Neutral: Participant expresses a neutral reaction to the app idea

Confusion: Participant is confused about app's use case and/or procedure
"Using an app to teach empathy, at least to me, appears to be totally counter-productive to faciliate (sic) the development of empathy." (woman, instructor/professor, Faculty of Social work)

"...place more resources in clinical exposure" (woman, student, Faculty of Health Sciences)

"I do not think such an app would be helpful." (man, student, University 1)

"neutral, no strong reaction" (woman, instructor/professor, did not indicate Faculty)

"I'm a little bit confused about exactly how it works, but I like the idea of it." (woman, student, did not indicate Faculty)

Question: What is your reaction to the In Your Shoes Mobile App? 
being useful); 3) Neutral reactions to the app idea; and 4) Confusion about its use. For example, one participant (woman, instructor/professor, Faculty of Health Sciences) wrote, "looks promising, relevant to all relationships/communication." Another (man, student, School of Business) wrote "alright." While another (man, student, Faculty of Science) wrote, "I don't think it is needed, you can just talk to the person to find out what they are thinking/feeling." Finally, one participant (woman, instructor/professor, did not report Faculty) wrote "I'm not sure what it does or what purpose it serves." These responses indicate varying support for the app idea and help clarify the sentiment analysis and word cloud results.

\subsection{Participants' responses to being unlikely to buy the app}

Participants who indicated that they would be unlikely to buy the app (i.e., they selected 1 or 2 on the question "how likely are you to consider buying the app") were asked about their response. Students were understandably somewhat negative given the nature of the question $(-18.3)$. Their word cloud indicated that responses focused on money, apps, and the word “don't." (e.g., "I don't buy apps”). Instructors/professors' responses were unexpectedly positive $(99.1){ }^{2}$ The associated word cloud focused on empathy and technology needing to add value to the course.

Three themes emerged from qualitative analyses that help us to understand the disinterest in buying the app: 1) responses indicating that participants did not think they fit the target market; 2) responses about money or purchasing apps in general; and 3) responses about the app itself (Table 4). Like the Target or Use Case theme for who would use the app, the first theme's categories included that the app is not relevant or that they lack interest in it. For example, one participant (woman, instructor/professor, Faculty of Social Work) wrote, "I have taught interpersonal communication skills for approximately 25 years - not necessary" The second theme's categories included rarely or never spending money on apps; preferring a free app or a free alternative to the app; and that the app would not be a priority purchase (not worth the money). For example, one participant (agender, student, Faculty of Arts) wrote, "I don't buy apps." Another (woman, student, School of Business) wrote, "I would only get the app if it had a free trial period to try it out." The third theme's categories related to perceptions of the app's effectiveness and the app's protocol (e.g., the app is impractical, privacy concerns, and confusion about the app's use case or procedure). For example, one participant (man, student, Faculty of Engineering) wrote, "low chance of repeated use, requires time commitment and analysis." Together, these responses provide additional insight into potential concerns, factors to consider when creating the app, and the target market (e.g., offer a free trial, ensure reliable security, promote broad applicability).

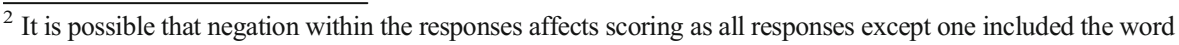
"not." Thus, responses like "not necessary" may have been interpreted positively. According to the site, "this tool produces an overall sentiment score. Although various passages within a sample of text may be particularly positive or negative, the sentiment score produced by this tool considers all of the text in the sample... Research shows that in about $20 \%$ of all cases human beings will disagree about the sentiment of written text." (https://www.danielsoper.com/sentimentanalysis/default.aspx)
} 
Table 4 Thematic expressions of disinterest in purchasing the App by participants

Examples

About the target: Participant believes they don't fit target market

Not relevant/no need: Participant states that the app is "not appropriate to my area of teaching" (man, not relevant to them or their field or states disbelief instructor/professor, Faculty of Environment, regarding the need for an app to teach empathy (e.g., they say that they are already empathetic)

Lack of interest: Participant lacks interest Earth, and Resources)

"There would never be a time when I would want to use this. The only way I would ever use it is if were part of a leadership training thing." (man, student, Faculty of Science)

About money: Participant makes a comment related to money or purchasing apps

Rarely or never spend money on apps: Participant says that they do not like purchasing apps or that they do so rarely

Free app or free alternative: Participant indicates that they would download the app if it were free, otherwise they would prefer a free alternative

Not worth the money: Participant indicates that the app is not a priority purchase
"I never pay for apps" (woman, student, Faculty of Agriculture and Food Sciences)

"If it were free I would consider downloading it" (woman, student, Faculty of Arts)

"I would not want to spend money on this" (woman, student, School of Art)

About the app: Participant makes a comment about the app itself

App's effectiveness: Participant is unconvinced of app's effectiveness

"Don't feel it would add value to my current practice" (woman, instructor/professor, Faculty of Health Sciences)

App's protocol: Participant makes a comment about the app's protocol

App is impractical: Participant comments that the app is impractical

Privacy: Participant makes a comment related to privacy/is concerned about privacy

Confusion about its use: Participant is confused about "I don't understand how/where you'd use the app" app's use case and procedure
"It does not seem very practical and the benefits to me would be minimal" (man, student, School of Business)

"I don't like the idea that my discussions could be recorded on my phone" (man, student, University 1) (woman, student, School of Business)

Question: If you are unlikely to consider buying the app, why not?

\subsubsection{Instructors/professors' responses to being unlikely to recommend buying the app}

Faculty who indicated that they would be unlikely to recommend buying the app (i.e., they selected 1 or 2 on the question "how likely are you to consider recommending buying the app") were asked about their response and (as would be expected given the nature of the question) responses were quite negative $(-69.1)$. The word cloud highlighted a focus on the classroom, skill development, empathy, and being unconvinced. Three themes emerged from qualitative analyses: 1) responses indicating that the app is not relevant to the participant or their field (mirroring responses to being unlikely to buy the app); 2) responses indicating skepticism that empathy can be taught with an app (i.e., they are not convinced); and 3) responses about money or purchasing apps (Table 5). For example, one participant (did not report gender, instructor/ 
Table 5 Thematic expressions of disinterest in recommending the App by Instructors/Professors

\begin{tabular}{ll}
\hline Themes & Examples \\
\hline $\begin{array}{c}\text { Not relevant: Participant states that the app is } \\
\text { not relevant to them or their field }\end{array}$ & $\begin{array}{c}\text { "not appropriate to my area" (man, Environment, Earth, and } \\
\text { Resources) } \\
\text { Not convinced: Participant is skeptical that } \\
\text { empathy can be taught with an app }\end{array}$ \\
$\begin{array}{c}\text { About the money: Participant makes a } \\
\text { comment related to money or purchasing } \\
\text { apps }\end{array}$ & $\begin{array}{c}\text { "depends on the price - instructors only have a professional } \\
\text { development fund - we must be selective of our ex- } \\
\text { penses" (woman, Environment, Earth, and Resources) }\end{array}$ \\
\hline
\end{tabular}

Question: If you are unlikely to consider recommending buying the app, why not? (Faculty only)

professor, Faculty of Arts) wrote, "I don't think they would use it and I'm not sure that I feel that an app is the best approach to learning empathy, so I'm not convinced on its utility." While another (did not report gender, instructor/professor, did not report Faculty) wrote, "Students have better things to spend their money on, however small the amount." Together, these responses provide additional insight into the target market and instructor perceptions of using technology to teach empathy.

\subsection{Which professions believe that cognitive empathy is important to their profession?}

Addressing Research Question 3 (which professions believe that cognitive empathy is important to their profession), $81 \%$ of students and $83 \%$ of instructors/professors said that cognitive empathy is important for their profession. Most participants $(60 \%$ or higher) from all 17 Faculties except one (School of Agriculture) thought that cognitive empathy was important for their profession (Table 6).

\section{Discussion}

The present research helps us progress towards the product-creation phase within the KTA framework to facilitate uptake of an evidence-based intervention more quickly into the classroom. Like other research (Farley et al. 2015; Nason et al. 2015; O'Connor and Andrews 2018; Williamson and Muckle 2018) over 90\% of participants owned and used a smartphone or tablet. Some, but not the majority, of instructors/professors were asking students to use mobile apps for their course work (see also Ariel and ElisharMalka 2019). This amount is likely to increase spurred by the COVID-19 pandemic. We also found that when considering the empathy-based app for class use, qualitative results echoed those found in previous research: Participants mentioned usefulness, money, the ability to use a trial version, and enjoyment (Kim et al. 2016). These variables are important because they predict intention to purchase an app (Kim et al. 2016). Together, results indicate a potentially large market for apps within higher education and that apps might be successful if perceived as useful, enjoyable, and triable. These findings are timely because there is a worldwide movement in education toward remote learning and using technology to deliver content (e.g., Bates 2020). 
Table 6 Student and Instructor/Professor perception of cognitive empathy's importance for their profession by faculty area

\begin{tabular}{|c|c|c|c|c|c|c|c|c|c|}
\hline \multirow[t]{2}{*}{ Faculty } & \multicolumn{3}{|c|}{$\begin{array}{l}\text { Student } \\
\text { responses }\end{array}$} & \multicolumn{3}{|c|}{$\begin{array}{l}\text { Faculty } \\
\text { responses }\end{array}$} & \multicolumn{3}{|c|}{ Total } \\
\hline & No & Yes & $\mathrm{N}$ & No & Yes & $\mathrm{N}$ & No & Yes & $\mathrm{N}$ \\
\hline Faculty of Agricultural and Food Sciences & 9 & 17 & 26 & 1 & 2 & 3 & 10 & 19 & 29 \\
\hline School of Agriculture & 1 & 0 & 1 & 1 & 0 & 1 & 2 & 0 & 2 \\
\hline Faculty of Architecture & 1 & 7 & 8 & - & - & - & 1 & 7 & 8 \\
\hline School of Art & 0 & 8 & 8 & - & - & - & 0 & 8 & 8 \\
\hline Faculty of Arts & 10 & 96 & 106 & 1 & 5 & 6 & 11 & 101 & 112 \\
\hline School of Business & 13 & 33 & 46 & 0 & 2 & 2 & 13 & 35 & 48 \\
\hline Faculty of Education & 0 & 16 & 16 & 0 & 2 & 2 & 0 & 18 & 18 \\
\hline Faculty of Engineering & 9 & 34 & 43 & - & - & - & 9 & 34 & 43 \\
\hline Faculty of Environment, Earth, and Resources & 2 & 13 & 15 & 1 & 1 & 2 & 3 & 14 & 17 \\
\hline Faculty of Health Sciences & 7 & 67 & 74 & 1 & 9 & 10 & 8 & 76 & 84 \\
\hline Faculty of Kinesiology and Recreation Management & 2 & 11 & 13 & - & - & - & 2 & 11 & 13 \\
\hline Faculty of Law & 0 & 5 & 5 & 0 & 1 & 1 & 0 & 6 & 6 \\
\hline Faculty of Music & 0 & 5 & 5 & - & - & - & 0 & 5 & 5 \\
\hline Faculty of Science & 35 & 74 & 109 & 1 & 5 & 6 & 36 & 79 & 115 \\
\hline Faculty of Social Work & 0 & 33 & 33 & 0 & 2 & 2 & 0 & 35 & 35 \\
\hline Extended Education & 1 & 11 & 12 & - & - & - & 1 & 11 & 12 \\
\hline University 1 & 23 & 55 & 78 & - & - & - & 23 & 55 & 78 \\
\hline Did not indicate Faculty & 1 & 13 & 14 & - & 1 & 1 & 1 & 14 & 15 \\
\hline Total & 114 & 498 & 612 & 6 & 30 & 36 & 120 & 528 & 648 \\
\hline
\end{tabular}

Our research adds to the literature by illuminating perceptions of app cost within education. The majority of participants said that they would prefer for the app to be free or less than $\$ 3$ for students. Most participants preferred a one-time payment option. They also preferred the ability to choose between a basic version of the app that is free and a version that has extra features and a cost over a free trial and later payment. Qualitative responses indicated that some participants just do not purchase apps. Additionally, student participants described being stretched for resources and unable to spend money on apps. Apps tend to be free and people often prefer free alternatives to having to pay (Hsu and Lin 2015). Thus, making the app free may increase uptake. App developers and marketers should consider making apps free for students and passing the cost on to institutions, when possible (see Table 7 for all recommendations). Doing so would allow a greater number and diversity of people to learn about concepts such as empathy.

Apps provide opportunities to advance changes in how content is being taught in and outside of the classroom. Currently, when instructors and researchers want to use paradigms like Ickes' (2001), they often require students to come into a lab (e.g., Lobchuk et al. 2016). This makes participating unfeasible and costly for many. Indeed, the present research indicates that cost is top of mind for students. The ubiquity of 
Table 7 Key recommendations to develop a mobile empathy App

\section{Recommendations}

1. Make the app free or for a minimal cost to students and pass the cost to institutions, when possible

2. Make the app a one-time payment for students

3. Prioritize targeting people in the fields of Business, Education, Health Sciences, and Law

4. Empathize the benefits of dialoguing, self-reflection, and actively taking another person's perspective in marketing communications

5. Provide tips on how to find a dialogue partner and draw on relevant context to engage in meaningful dialogue

6. Engage in testing to ensure app security and communicate this security to users

7. Conduct usability testing to ensure a seamless user experience and reduce procedural barriers

8. Develop a compelling marketing strategy that highlights benefits gained across a variety of disciplines as indicated from previous research. Developing concrete examples of when the app could be used and including testimonials would be helpful

mobile devices that have access to cameras opens up new opportunities for participating in such paradigms. People can use their devices to help them to become aware of personal values that can impede empathy (Lobchuk et al. 2012); receive instruction (Lelorain et al. 2012) and feedback (Noordman et al. 2012); and self-evaluate with video-feedback (Fukkink et al. 2011) so that their perspective-taking ability improves. The present research indicates that people recognize the value that a cognitive empathy app can hold and how it can be used.

The present research also highlights concerns that people have about using apps for empathy instruction. We found that some people are wary of using their personal devices for recording conversations and being vulnerable. These people might benefit from coming into the lab and participating in a safe experience before using the app, as well as from receiving tips on finding a dialogue partner and drawing on relevant context to engage in a meaningful dialogue. Testing to ensure app security and communicating this security to users will also be important as will be ensuring a seamless experience and reducing procedural barriers via usability testing. Additionally, our research finds that some people might need to be convinced of the benefits of using technology to teach empathy skills. Developing a compelling marketing strategy that demonstrates how mobile devices can improve confidence (Koohestani et al. 2018) and performance (Dunleavy et al. 2019), and cites evidence of the intervention's effectiveness might be beneficial here. The present research indicates that many people recognize the importance of cognitive empathy for interpersonal relationships and for their profession. Convincing them that it can be taught with technology would ensure that more people get the instruction that they need.

Consistent with previous research (Keyworth et al. 2013), students want communication skills training. While previous research has studied cognitive empathy within a variety of fields (e.g., Teding van Berkhout and Malouff 2016), the present research indicates that more fields are interested in it than likely previously thought. Participants were interested in the app idea, with those in Education, Social Work, and Health Sciences among the most interested. Even participants in the physical sciences were interested and believed that cognitive empathy is important to their profession despite other research finding that being low in cognitive empathy predicts enrollment in the 
physical sciences (Thomson et al. 2015). Perhaps they are aware of being low and want to improve their perspective-taking skills because they believe it is important for their profession. Future research should investigate this further.

The confusion and questions about the app protocol as well as the varying sentiment about the app indicates that more research is needed. Future research will iterate app descriptions and wireframes to increase clarity and value of the app. Scenarios where the app might be used will be guided by research and used in marketing so that the value of the app (e.g., trust-building; Blatt et al. 2010) is evident to a wider range of people. One reason why increasing perceived value will be important is because it predicts app purchase intentions (Hsu and Lin 2015). While the present research was a necessary first step into assessing perceptions of the concept idea, future research will also indicate how perceptions of the app and the idea of using technology to teach cognitive empathy changes as people start interacting with app prototypes.

\subsection{Limitations and strengths}

One limitation to this study is participant self-selection bias: the people who opted to participate in a study about empathy may have been more interested in this topic than others. This is evident, for example, in the number of instructors/professors who indicated that they taught courses having to do with interpersonal communication (53\%), as well as the greater participation from people who participated in certain fields (i.e., Health Sciences, Education). While we received student participation from every faculty area, this participation was not equal and there was less representation among instructors/professors. It is possible that we would have received a wider variety of responses had participants not known the app's topic (empathy) prior to starting the study. Stating that the study focused on an instructional app or an app on communication skills (without mentioning empathy) might have increased the variability. Generalizability is also limited because the sample was restricted to one Canadian university. Future pre-registered research examining perceptions of empathy's importance across disciplines should include a greater number of participants from diverse areas and could examine interest in an empathy app with a non-student population. For example, corporations may have more resources and be more interested in furthering the empathy of their employees than those within educational institutions. Additionally, the survey was accessible during a busy month (December), thus people may have been more likely to participate had it occurred in a different month. Moreover, the survey contained some adapted and investigator-developed questions that would benefit from additional validation. Future research could conduct cognitive interviews to ensure that questions are being interpreted as they were written.

Despite these limitations, this research has a number of strengths, including the use of multiple methods and analysis techniques (Morse 2015). Our methods allowed us to identify potential barriers to uptake, which is a step in the KTA framework (Graham et al. 2006). Potential user feedback spotlighted critical features to incorporate in an empathy app that is designed to foster targeted, meaningful, and efficient learning which can be differentiated based on discipline or profession. Additionally, to our knowledge, this is the first study that has examined perceptions of the importance of cognitive empathy across a broad range of fields/professions. Our finding that participants in a variety of fields/professions find cognitive empathy important will be of interest to people studying empathy, marketing, and education. 


\section{Conclusions}

Taking the perspective of another and understanding where they are coming from is an essential skill for many professions. Thus, being able to teach cognitive empathy effectively and accessibly is an important goal for instructors. As impacted by the COVID-19 pandemic, efforts in restructuring how we teach in basic and continuing education are reflective of increasing reliance on technology-based learning. Not everyone is enthusiastic about using technology in empathy education. Some people are concerned that technology impedes empathy and learning by, for example, acting as a barrier between people. However, we believe that, done correctly, technology can instead act as a bridge.

Availability of data and material Consent was not provided to share non-aggregated data. Materials and word clouds are available on the Open Science Framework: https://osf.io/bh9su/?view_only=0ff44fe143914 $\mathrm{e} 0088 \mathrm{c} 1 \mathrm{f} 5 \mathrm{~d} 54 \mathrm{ac} 7 \mathrm{f} 8 \mathrm{c} 6$

Funding information This research did not receive any specific grant from funding agencies in the public, commercial, or not-for-profit sectors, nor has the app development received any funding to date.

\section{Compliance with ethical standards}

Conflicts of interest/competing interests The results of the present research are being used to guide development of an evidence-based empathy app that the first two authors are creating.

Code availability Not applicable.

\section{References}

Alwraikat, M., \& Tokhaim, H. A. (2014). Exploring the potential of mobile learning use among faculty members. International Journal of Interactive Mobile Technologies, 8(3), 4-10. https://doi.org/10.3991 /ijim.v8i3.3682.

Ariel, Y., \& Elishar-Malka, V. (2019). Learning in the smartphone era: Viewpoints and perceptions on both sides of the lectern. Education and Information Technologies, 24(4), 2329-2340. https://doi.org/10.1007 /s10639-019-09871-w.

Bandes, S. A. (2009). Empathetic judging and the rule of law. Cardozo Law Review De Novo., 133148. https://ssrn.com/abstract=1431230.

Bates, T. (2020). Online enrolments after COVID-19: Some predictions for Canada. University Affairs. https://www.universityaffairs.ca/opinion/in-my-opinion/online-enrolments-after-covid-19-somepredictions-for-canada/

Batson, C. D., \& Ahmad, N. Y. (2009). Using empathy to improve intergroup attitudes and relations. Social Issues and Policy Review, 3(1), 141-177. https://doi.org/10.1111/j.1751-2409.2009.01013.x.

Blanch-Hartigan, D., \& Ruben, M. A. (2013). Training clinicians to accurately perceive their patients: Current state and future directions. Patient Education and Counseling, 92(3), 328-336. https://doi.org/10.1016/j. pec.2013.02.010.

Blatt, B., LeLacheur, S. F., Galinsky, A. D., Simmens, S. J., \& Greenberg, L. (2010). Does perspective-taking increase patient satisfaction in medical encounters? Academic Medicine, 85(9), 1445-1452. https://doi. org/10.1097/acm.0b013e3181 eae5ec.

Brunero, S., Lamont, S., \& Coates, M. (2010). A review of empathy education in nursing. Nursing Inquiry, 17(1), 65-74. https://doi.org/10.1111/j.1440-1800.2009.00482.x. 
Burkhardt, H., \& Schoenfeld, A. H. (2003). Improving educational research: Toward a more useful, more influential, and better-funded enterprise. Educational Researcher, 32(9), 3-14. https://doi.org/10.3102 /0013189X032009003.

Chen \& deNoyelles (2013). Exploring students' mobile learning practices in higher education. EDUCAUSEreview. https://er.educause.edu/articles/2013/10/exploring-students-mobile-learningpractices-in-higher-education

Cotter, J. J., Gendron, T., Kupstas, P., Tartaglia, A., \& Will, L. (2015). Perceived benefits of mobile learning devices for doctoral students in a school of allied health professionals. Journal of Allied Health, 44(4), e29-e35. https://pubmed.ncbi.nlm.nih.gov/26661706/.

Crompton, H., \& Burke, D. (2018). The use of mobile learning in higher education: A systematic review. Computers in Education, 123, 53-64. https://doi.org/10.1016/j.compedu.2018.04.007.

Cunico, L., Sartori, R., Marognolli, O., \& Meneghini, A. M. (2012). Developing empathy in nursing students: A cohort longitudinal study. Journal of Clinical Nursing, 21(13-14), 2016-2025. https://doi.org/10.1111 j.1365-2702.2012.04105.x.

Davis, M. A. (2009). A perspective on cultivating clinical empathy. Complementary Therapies in Clinical Practice, 15(2), 76-79. https://doi.org/10.1016/j.ctcp.2009.01.001.

Davis, M. H. (2015). Empathy and prosocial behavior. In D. A. Schroeder \& W. G. Graziano (Eds.), Oxford library of psychology. The Oxford handbook of prosocial behavior (pp. 282-306). New York: Oxford University Press. https://doi.org/10.1093/oxfordhb/9780195399813.013.026.

Dunleavy, G., Nikolaou, C. L., Nifakos, S., Atun, R., Law, G. C. Y., \& Car, L. T. (2019). Mobile digital education for health professions: Systematic review and meta-analysis by the digital health education collaboration. Journal of Medical Internet Research, 21(2), e12937. https://doi.org/10.2196/12937.

Elo, S., Kaariainen, M., Kanste, O., Polkki, T., Utriainen, K., \& Kyngas, H. (2014). Qualitative content analysis: A focus on trustworthiness. SAGE Open, 4(1), 1-10. https://doi.org/10.1177 $/ 2158244014522633$.

Farley, H., Murphy, A., Johnson, C., Carter, B., Lane, M., Midgley, W., Hafeez-Baig, A., Dekeyser, S., \& Koronios, A. (2015). How do students use their mobile devices to support learning? A case study from an Australian regional university. Journal of Interactive Media in Education, 14, 1-13. https://doi. org/10.5334/jime.ar.

Fukkink, R. G., Trienekens, N., \&, Kramer, L. J. C. (2011). Video feedback in education and training: Putting learning in the picture. Educational Psychology Review, 23(1), 45-63. https://doi.org/10.1007/s10648010-9144-5.

Galinsky, A. D., Ku, G., \& Wang, C. S. (2005). Perspective-taking and self-other overlap: Fostering social bonds and facilitating social coordination. Group Processes \& Intergroup Relations, 8(2), 109-124. https://doi.org/10.1177/1368430205051060.

Government of Canada. (2016). About us: Knowledge Translation - CIHR. http://www.cihr-irsc.gc. $\mathrm{ca} / \mathrm{e} / 29418 . h t m l$.

Graham, I. D., Logan, J., Harrison, M. B., Straus, S. E., Tetroe, J., Caswell, W., \& Robinson, N. (2006). Lost in knowledge translation: Time for a map? The Journal of Continuing Education in the Health Professions, 26(1), 13-24. https://doi.org/10.1002/chp.47.

Graneheim, U. H., \& Lundman, B. (2004). Qualitative content analysis in nursing research: Concepts, procedures and measures to achieve trustworthiness. Nurse Education Today, 24(2), 105-112. https://doi.org/10.1016/j.nedt.2003.10.001.

Hao, S., Dennen, V. P., \& Mei, L. (2017). Influential factors for mobile learning acceptance among Chinese users. Educational Technology Research and Development, 65, 101-123. https://doi.org/10.1007/s11423016-9465-2.

Hoplock, L. B., \& Lobchuk, M. M. (2019a). Are perspective-taking outcomes always positive? Challenges and mitigation strategies. Nursing Forum, 55, 1-4. https://doi.org/10.1111/nuf.12413.

Hoplock, L. B. \& Lobchuk, M. M. (2019b). Qualitative insights into adapting an in-lab empathy intervention for use via videoconference with groups of nursing students, [unpublished manuscript]. https://doi. org/https://doi.org/10.5203/b3ve-7e41.

Hsu, C.-L., \& Lin, J. C.-C. (2015). What drives purchase intention for paid mobile apps? An expectation confirmation model with perceived value. Electronic Commerce Research and Applications, 14(1), 4657. https://doi.org/10.1016/j.elerap.2014.11.003.

Hsueh, W. D., Bent, J. P., \& Moskowitz, H. S. (2018). An app to enhance resident education in otolaryngology. The Laryngoscope, 128(6), 1340-1345. https://doi.org/10.1002/lary.27040.

Ickes, W. (2001). Measuring empathic accuracy. In J. A. Hall \& F. J. Bernieri (Eds.), Interpersonal sensitivity: Theory and measurement (pp. 219-241). Mahwah: Lawrence Erlbaum Associates Publishers https://psycnet.apa.org/record/2001-01720-012. 
Keyworth, C., Peters, S., Chisholm, A., \& Hart, J. (2013). Nursing students' perceptions of obesity and behaviour change: Implications for undergraduate nurse education. Nurse Education Today, 33(5), 481485. https://doi.org/10.1016/j.nedt.2012.05.016.

Kilpatrick, S. D., Bissonnette, V. L., \& Rusbult, C. E. (2003). Empathic accuracy and accommodative behavior among newly married couples. Personal Relationships, 9(4), 369-393. https://doi.org/10.1111 /1475-6811.09402.

Kim, S., Kaplowitz, S., \& Johnston, M. (2004). The effects of physician empathy on patient satisfaction and compliance. Evaluation \& the Health Professions, 27, 237-251. https://doi.org/10.1177 /0163278704267037.

Kim, H.-W., Kankanhalli, A., \& Lee, H. L. (2016). Investigating decision factors in mobile application purchase: A mixed-methods approach. Information and Management, 53(6), 727-739. https://doi. org/10.1016/j.im.2016.02.011.

Koohestani, H. R., Arabshahi, S. K. S., Fata, L., \& Ahmadi, F. (2018). The educational effects of mobile learning on students of medical sciences: A systematic review in experimental studies. Journal of Advances in Medical Education \& Professionalism, 6(2), 58-69. https://pubmed.ncbi.nlm.nih. gov/29607333/.

Ku, G., Wang, C. S., \& Galinsky, A. D. (2015). The promise and perversity of perspective-taking in organizations. Research in Organizational Behavior, 35, 79-102. https://doi.org/10.1016/j. riob.2015.07.003.

Langmia, K., \& Glass, A. (2014). Coping with smart phone 'distractions' in a college classroom. Teaching Journalism and Mass Communication, 4(1), 13-23. http://www.aejmc.us/spig/journal.

Lelorain, S., Brédart, A., Dolbeault, S., \& Sultan, S. (2012). A systematic review of the associations between empathy measures and patient outcomes in cancer care. Psychooncology, 21(12), 1255-1264. https://doi. org/10.1002/pon.2115.

Levitt, H. M., Bamberg, M., Creswell, J. W., Frost, D. M., Josselson, R., \& Suárez-Orozco, C. (2018). Journal article reporting standards for qualitative primary, qualitative, meta- analytic, and mixed methods research in psychology: The APA publications and communications board task force report. American Psychologist, 73(1), 26-46. https://doi.org/10.1037/amp0000151.

Lincoln, Y. S., \& Guba, E. G. (1985). Naturalistic inquiry. Beverly Hills: Sage Publications Inc https://us. sagepub.com/en-us/nam/naturalistic-inquiry/book842.

Lobchuk, M. M., McClement, S. E., McPherson, C. J., \& Cheang, M. (2012). Impact of patient smoking behaviour on empathic helping by family caregivers in lung cancer. Oncology Nursing Forum, 39(2), E112-E121. https://doi.org/10.1188/12.onf.e112-e121.

Lobchuk, M., Halas, G., West, C., Harder, N., Tursunova, Z., \& Ramraj, C. (2016). Development of a novel empathy-related video-feedback intervention to improve empathic accuracy of nursing students: A pilot study. Nurse Education Today, 46, 86-93. https://doi.org/10.1016/j.nedt.2016.08.034.

Lobchuk, M., Hoplock, L. B., Halas, G., West, C., Schroeder, W., Ashcroft, T., Chambers Clouston, K., \& Lemoine, J. (2018). Heart health whispering: A randomized, controlled pilot study to promote nursing student perspective-taking on carers' unhealthy lifestyle choices. BMC Nursing, 17. https://oi. org/10.1186/s12912-018-0291-1.

Marangoni, C., Garcia, S., Ickes, W., \& Teng, G. (1995). Empathic accuracy in a clinically relevant setting. Journal of Personality and Social Psychology, 68(5), 854-869. https://doi.org/10.1037/00223514.68.5.854.

Morse, J. M. (2015). Critical analysis of strategies for determining rigor in qualitative inquiry. Qualitative Health Research, 25(9), 1212-1222. https://doi.org/10.1177/1049732315588501.

Nason, G. J., Burke, M. J., Aslam, A., Kelly, M. E., Akram, C. M., Giri, S. K., \& Flood, H. D. (2015). The use of smartphone applications by urology trainees. The Surgeon, 13(5), 263-266. https://doi.org/10.1016/j. surge.2014.06.00.

Nguyen, L., Barton, S. M., \& Nguyen, L. T. (2015). iPads in higher education - Hype and hope. British Journal of Educational Technology, 46(1), 190-203. https://doi.org/10.1111/bjet.12137.

Noordman, J., van der Weijden, T., \& van Dulmen, S. (2012). Communication-related behaviour change techniques used in face-to-face lifestyle interventions in primary care: A systematic review of the literature. Patient Education and Counseling, 89(2), 227-244. https://doi.org/10.1016/j.pec.2012.07.006.

Norris, C., Hossain, A., \& Soloway, E. (2011). Using smartphones as essential tools for learning. Educational Technology, 51(3), 18-25. https://eric.ed.gov/?id=EJ936510.

O’Connor, S., \& Andrews, T. (2018). Smartphones and mobile applications (apps) in clinical nursing education: A student perspective. Nurse Education Today, 69, 172-178. https://doi.org/10.1016/j. nedt.2018.07.013. 
Parker, S. K., Atkins, P. W. B., \& Axtell, C. M. (2008). Building better workplaces through individual perspective taking: A fresh look at a fundamental human process. In G. P. Hodgkinson \& J. K. Ford (Eds.), International review of industrial and organizational psychology (pp. 149-196). Chichester: Wiley http:/citeseerx.ist.psu.edu/viewdoc/download?doi=10.1.1.536.6376\&rep=rep1\&type=pdf.

Patton, M. (2002). Qualitative research \& evaluation methods (3rd ed.). Thousand Oaks: Sage Publications https://www.jstor.org/stable/40319463.

Richardson, C., Percy, M., \& Hughes, J. (2015). Nursing therapeutics: Teaching student nurses care, compassion and empathy. Nurse Education Today, 35(5), e1-e5. https://doi.org/10.1016/j. nedt.2015.01.016.

Saldana, J. (2009). The coding manual for qualitative researchers. SAGE Publications Ltd. https://stevescollection.weebly.com/uploads/1/3/8/6/13866629/saldana_2009_the-coding-manual-forqualitative-researchers.pdf

Sened, H., Lavidor, M., Lazarus, G., Bar-Kalifa, E., Rafaeli, E., \& Ickes, W. (2017). Empathic accuracy and relationship satisfaction: A meta-analytic review. Journal of Family Psychology, 31(6), 742-752. https://doi.org/10.1037/fam0000320.

Sevillano-Garcia, M. L., \& Vazquez-Cano, E. (2015). The impact of digital mobile devices in higher education. Educational Technology \& Society, 18(1), 106-118. https://eric.ed.gov/?id=EJ1062522.

Simmons, J. P., Nelson, L. D., \& Simonsohn, U. (2011). False-positive psychology: Undisclosed flexibility in data collection and analysis allows presenting anything as significant. Psychological Science, 22(11), 1359-1366. https://doi.org/10.1177/0956797611417632.

Simmons, J. P., Nelson, L. D. \& Simonsohn, U. (2012). A 21 Word Solution. https://doi.org/10.2139 /ssrn.2160588

Soper, D. (n.d.). Sentiment analyzer. https://www.danielsoper.com/sentimentanalysis/default.aspx

Statistics Canada. (2020). Table 11-10-0008-01 Tax filers and dependants with income by total income, sex and age. https://doi.org/10.25318/1110000801-eng.

SurveyMonkey. (n.d.). Product testing survey template. https://www.surveymonkey.com/mp/product-testingsurvey-template/

Teding van Berkhout, E., \& Malouff, J. M. (2016). The efficacy of empathy training: A meta- analysis of randomized controlled trials. Journal of Counseling Psychology, 63(1), 32-41. https://doi.org/10.1037 /cou0000093.

Thomas, G., \& Fletcher, G. J. O. (2003). Mind-reading accuracy in intimate relationships: Assessing the roles of the relationship, the target, and the judge. Journal of Personality and Social Psychology, 85(6), 10791094. https://doi.org/10.1037/0022-3514.85.6.1079.

Thomson, N. D., Wurtzburg, S. J., \& Centifanti, L. C. M. (2015). Empathy or science? Empathy explains physical science enrollment for men and women. Learning and Individual Differences, 40, 115-120. https://doi.org/10.1016/j.lindif.2015.04.003.

Verhofstadt, L., Devoldre, I., Buysse, A., Stevens, M., Hinnekens, C., Ickes, W., \& Davis, M. (2016). The role of cognitive and affective empathy in spouses' support interactions: An observational study. PLoS One, 11(2), e0149944. https://doi.org/10.1371/journal.pone.0149944.

Vorauer, J. (2013). The case for and against perspective-taking. In Olson, J. M. \& Zanna, M. P., (Eds.), Advances in Experimental Social Psychology, 48, 59-115. Elsevier Academic Press. https://psycnet.apa. org/record/2013-25351-002

Vorauer, J. D., \& Sasaki, S. J. (2014). Distinct effects of imagine-other versus imagine-self perspective-taking on prejudice reduction. Social Cognition, 32(2), 130-147. https://doi.org/10.1521/soco.2014.32.2.130.

Vrana, R. (2018). Acceptance of mobile technologies and m-learning in higher education learning: an explorative study at the Faculty of Humanities and Social Science at the University of Zagreb [paper presentation]. Electronics and microelectronics 41st international convention on information and communication technology, Opatija, Croatia.

Williamson, K. M., \& Muckle, J. (2018). Students' perception of technology use in nursing education. Computers, Informatics, Nursing, 36(2), 70-76. https://doi.org/10.1097/CIN.0000000000000396.

Publisher's note Springer Nature remains neutral with regard to jurisdictional claims in published maps and institutional affiliations. 